\title{
PARTISIPASI PEMUDA PADA WISATA ALAM KALIBIRU
}

\author{
Lilik Prasaja ${ }^{1}$, Saryani $^{2}$, Muhamad $^{3}$ \\ ${ }^{1}$. Sekolah Pascasarjana, Universitas Gadjah Mada \\ lilikprasaja@gmail.com
}

\begin{abstract}
ABSTRAK
Pariwisata merupakan sektor yang sedang berkembang pesat di berbagai wilayah Indonesia. Pariwisata berbasis komunitas menjadi daya tarik baru yang memberdayakan komunitas lokal dengan menerapkan praktik-praktik pariwisata berkelanjutan. Pemuda sebagai bagian dari komunitas lokal sering berpartisipasi secara langsung dalam pariwisata berbasis masyarakat. Penelitian ini ingin mengungkap implikasi partisipasi pemuda dalam sektor pariwisata. Wisata Alam Kalibiru dipilih sebagai lokus penelitian karena merupakan representasi pariwisata berkelanjutan yang telah dikenal di tingkat nasional dan internasional. Penelitian ini menggunakan teori-teori mengenai partisipasi dan pariwisata berbasis masyarakat. Penelitian ini menggunakan pendekatan campuran (mixed methods) dengan penekanan pada pendekatan kuantitatif. Pendekatan kuantitatif dilakukan menggunakan kuesioner dengan melibatkan 30 responden pemuda yang terlibat dalam aktivitas pariwisata di Wisata Alam Kalibiru. Pendekatan kualitatif digunakan untuk memperkaya serta mengonfirmasi data yang didapat dari pendekatan kuantitatif. Hasil dari penelitian ini adalah tingkat partisipasi pemuda masih ada di bawah tingkat partisipasi masyarakat secara umum. Generasi yang lebih tua masih memegang posisi-posisi utama dalam pengelolaan Wisata Alam Kalibiru. Perlu adanya proses transisional yang komprehensif untuk menjamin keberlangsungan Wisata Alam Kalibiru di masa depan.
\end{abstract}

Kata kunci: pemuda, pariwisata berbasis masyarakat, kalibiru.

\begin{abstract}
Tourism was a highly developing sector on various regions in Indonesia. Community-based tourism became new attractions which empowered local communities by implementing sustainable tourism practices. Youth as part of local communities often directly participated in community-based tourism. This research wanted to discover the quality of youth participation in tourism. Wisata Alam Kalibiru (Kalibiru Natural Tourism) had been chosen as locus of study because was a representation of a wellknown sustainable tourism in both national and international level. This research was using theories on participation and community-based tourism. This research had used mixed methods approach with emphasize on quantitative approach. The quantitative approach had involved 30 youth participated in "Wisata Alam Kalibiru" as respondents. The qualitative approach used to enrich and confirm generated data from quantitative approach. The result was found that youth participation level was still below the general community participation level. The older generation was still holding the main positions in Wisata Alam Kalibiru management. There was need for a comprehensive transitional process to ensure the sustainability of Wisata Alam Kalibiru in the future.
\end{abstract}

Keywords: youth, participation, community-based tourism, kalibiru

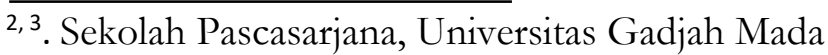




\section{PENDAHULUAN}

Pariwisata Indonesia dewasa ini berkembang pesat, salah satunya ditandai dengan banyaknya destinasi baru yang muncul dan populer. Sektor pariwisata di Daerah Istimewa Yogyakarta (DIY) termasuk Kabupaten Kulon Progo juga berkembang pesat. Dinas Pariwisata DIY dalam Statistik Kepariwisataan Tahun 2016 (rilis 2017) mencatat terdapat 4.549.574 wisatawan (domestik dan mancanegara) dengan tren yang terus naik. Statistik Kepariwisataan DIY menyebutkan bahwa wisatawan yang tercatat mengunjungi daya tarik wisata di Kulon Progo juga terus mengalami kenaikan. Data tahun 2016 menunjukkan secara agregat tercatat 1.353.400 wisatawan yang mengunjungi berbagai daya tarik wisata di Kulon Progo.

Wisata Alam Kalibiru merupakan salah satu daya tarik wisata utama di Kabupaten Kulon Progo. Kalibiru sendiri diambil dari nama dusun yakni Dusun Kalibiru di Desa Hargowilis, Kecamatan Kokap, Kabupaten Kulon Progo, Daerah Istimewa Yogyakarta. Wilayah tersebut terletak di perdesaan dengan kontur wilayah perbukitan. Wilayah perdesaan dan perbukitan seperti ini secara umum dipandang kurang memiliki potensi ekonomi dibandingkan wilayah

perkotaan. Bagi pemuda, menetap dan bekerja di wilayah seperti ini dipandang kurang menjanjikan, sehingga urbanisasi menjadi pilihan rasional.

Wisata Alam Kalibiru sebagai destinasi wisata menjadi penggerak ekonomi di wilayah tersebut, baik secara langsung maupun tidak langsung. Penelitian ini fokus pada partisipasi pemuda dalam pengelolaan Wisata Alam Kalibiru. Berdasarkan observasi, jumlah pemuda yang terlibat di Wisata Alam Kalibiru cukup signifikan dibandingkan dengan kelompok usia lain.

\section{METODE PENELITIAN}

Penelitian ini merupakan jenis penelitian campuran (mixed methods) dengan penekanan pada aspek kuantitatif. Penelitian campuran merupakan penelitian yang mengombinasikan antara pendekatan kuantitatif dengan kualitatif (Creswell 2010:5), sehingga diperoleh data yang lebih komprehensif, valid, reliabel, dan objektif dibandingkan dengan hanya menggunakan salah satu pendekatan saja. Mixed Method Research bertujuan untuk mengatasi kelemahan-kelemahan yang ada pada pendekatan kuantitatif maupun pendekatan kualitatif. (Sugiyono 2013:8).

Sesuai dengan metode penelitian campuran, maka teknik pengumpulan data dalam penelitian ini akan dilakukan dengan beberapa cara, yaitu: 1) kepustakaan, 2) observasi, 3) kuesioner, dan 4) wawancara. Penelitian ini mengambil populasi pemuda yang berpartisipasi dalam pengelolaan Wisata Alam Kalibiru. Sesuai dengan wawancara dengan pengelola pada penelitian pendahuluan, terdapat sekitar 50 orang pemuda yang berpartisipasi dalam pengelolaan Wisata Alam Kalibiru. Peneliti menetapkan sampel dari populasi tersebut sejumlah 30 orang pemuda 
yang menjadi terlibat secara reguler Wisata Alam Kalibiru. Selain karena jumlah populasi yang terbatas, angka 30 telah memenuhi jumlah minimum sampel untuk pengujian alat ukur (Roscoe dalam Sugiyono (2013:90)).

Penelitian ini menggunakan uji validitas Corrected Item Total Correlation (CITC), yang dapat dilihat pada tabel Item Statistics. Item pernyataan dinyatakan valid apabila CITC $>$ nilai $\mathrm{r}$ kritis. R kritis ditentukan dengan melihat $r$ tabel dengan $d f=$ jumlah sampel -2 . Estimasi reliabilitas dalam penelitian ini dilakukan dengan menggunakan komputer, yaitu menggunakan aplikasi SPSS version 22 dengan program uji keandalan teknik Alpa Cronbach's.

\section{KERANGKA TEORI}

\section{Partisipasi Masyarakat}

Arnstein (1969) mengemukakan bahwa partisipasi masyarakat merupakan bentuk kekuatan masyarakat ("Citizen participation is citizen power"). Arstein mengemukakan delapan tingkat partisipasi yang diilustrasikan sebagai model "tangga partisipasi masyarakat" ("The Ladder of Citizen Participation"). Delapan level tersebut adalah 1) manipulation, 2) therapy, 3) informing, 4) consultation, 5) placation, 6) partnership, 7) delegated power, dan 8) citizen control. Ke-delapan level partisipasi tersebut dibagi ke dalam tiga kategori yaitu nonparticipation, tokenism, dan citizen power. Selengkapnya dapat disimak dalam gambar 1 berikut ini:

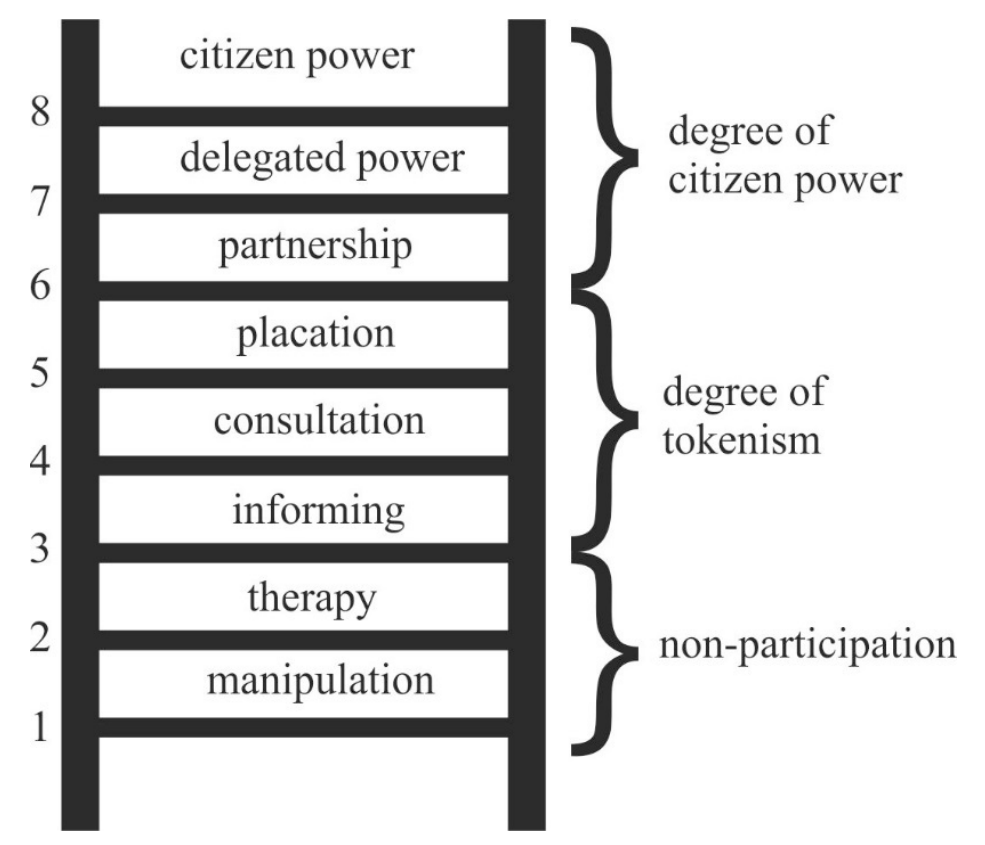

Gambar 1. Model Tangga Partisipasi Masyarakat Sumber: Digambar ulang oleh peneliti dari Arnstein, 1969:217. 
Tangga partisipasi Arnstein menjelaskan mengenai cara mengukur kualitas partisipasi masyarakat dalam sebuah kegiatan. Melalui tangga partisipasi tersebut dapat dipetakan kualitas partisipasi pemuda pada aktivitas pariwisata di Wisata Alam Kalibiru. Semakin tinggi tingkatan partisipasi pemuda, maka dapat diprediksi semakin besar pengaruhnya terhadap keseluruhan aktivitas pariwisata.

Jans dan de Backer (2002) berpendapat bahwa pemuda akan berpartisipasi aktif dalam masyarakat (society) apabila terdapat keseimbangan di antara tiga dimensi dalam model triangular mereka, yaitu: challenge (tantangan), capacity (kapasitas diri), dan connection (keterhubungan). Pertama, pemuda harus merasakan tantangan yang membuat mereka mau terlibat. Kedua, pemuda merasa dapat membuat perbedaan terhadap tantangan tersebut dengan kapasitas mereka. Ketiga, pemuda harus merasa terhubung dan didukung oleh berbagai pihak dalam menjawab tantangan tersebut.

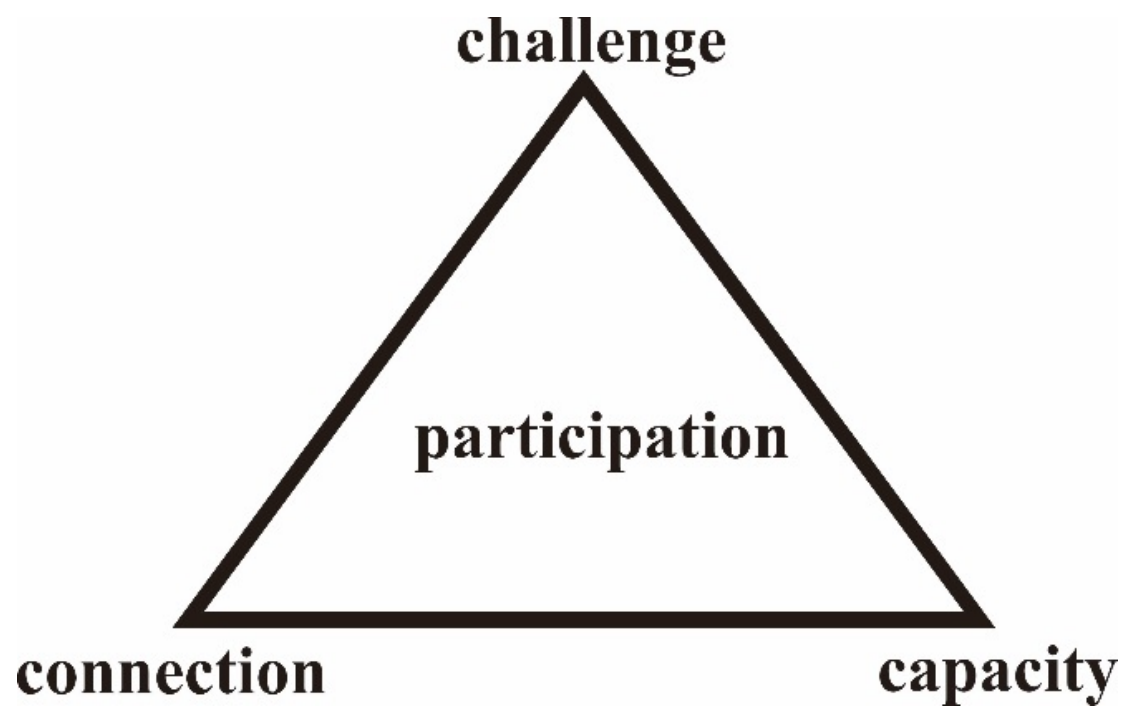

Gambar 2. Segitiga Partisipasi Pemuda Sumber: Jans dan de Backer (2002)

\section{Pariwisata Berbasis Masyarakat}

Community-based tourism (CBT) atau Pariwisata berbasis komunitas adalah jenis pariwisata unik yang karakternya cukup berbeda dari pariwisata massal. CBT tidak berorientasi memaksimalkan profit bagi investor, namun lebih kepada dampak yang ditimbulkan terhadap komunitas dan lingkungan. CBT ditumbuhkan dan dikelola oleh masyarakat. Meskipun demikian, CBT juga mewarisi masalah-masalah yang ada di masyarakat dan lingkungan tersebut. Sehingga apabila diaplikasikan sembarangan hanya akan membawa permasalahan dan bencana (Suansri 2003:11). 
Pariwisata berkelanjutan (sustainable tourism) pada dasarnya adalah penerapan prinsip-prinsip pertumbuhan yang berkelanjutan (sustainable development) pada sektor pariwisata. Yaitu pariwisata yang menjamin pemenuhan kebutuhan sekarang, tanpa mengorbankan kemampuan generasi selanjutnya dalam memenuhi kebutuhan mereka (Weaver 2006). Berbeda dari sektor ekonomi lain, sustainable tourism fokus pada praktik-praktik industri berkelanjutan. Pariwisata berkelanjutan dipandang sebagai industri yang memengaruhi semua sektor ekonomi lokal, mempekerjakan banyak orang dengan berbagai tingkat keahlian (skill). Munculnya pariwisata berkelanjutan menjadi peluang sekaligus tantangan bagi komunitas lokal (Wearing dan Neil 2009).

\section{PEMBAHASAN}

Berdasarkan kategorisasi nilai partisipasi, maka data empirik yang dianalisis menggunakan norma subjektif, subjek penelitian dapat dirinci sebagai berikut:

Tabel 1. Kategorisasi Variabel Partisipasi

\begin{tabular}{ccc}
\hline \hline Kategorisasi & Frekuensi Subjek & Persentase (\%) \\
\hline Baik & 5 & $16,7 \%$ \\
\hline Cukup & 21 & $70 \%$ \\
\hline Kurang & 4 & $13,3 \%$ \\
\hline Sumber: Analisis data primer (2018) &
\end{tabular}

Hasil penelitian menggambarkan bahwa subjek yang memiliki nilai partisipasi yang baik sebanyak 5 orang (16,7\%), kategori cukup sebanyak 21 orang (70\%), dan kategori kurang sebanyak 4 orang (13,3\%). Berdasarkan jumlah tersebut dapat dikatakan pemuda cukup berpartisipasi di Wisata Alam Kalibiru.

Berdasarkan jawaban atas kuesioner yang diberikan, dapat diketahui bahwa sumbangan efektif partisipasi pemuda tertinggi ditunjukkan dalam bentuk pemikiran $(35,7 \%)$ dan tenaga fisik $(33,3 \%)$. Hasil selengkapnya dapat dilihat pada grafik berikut ini: 


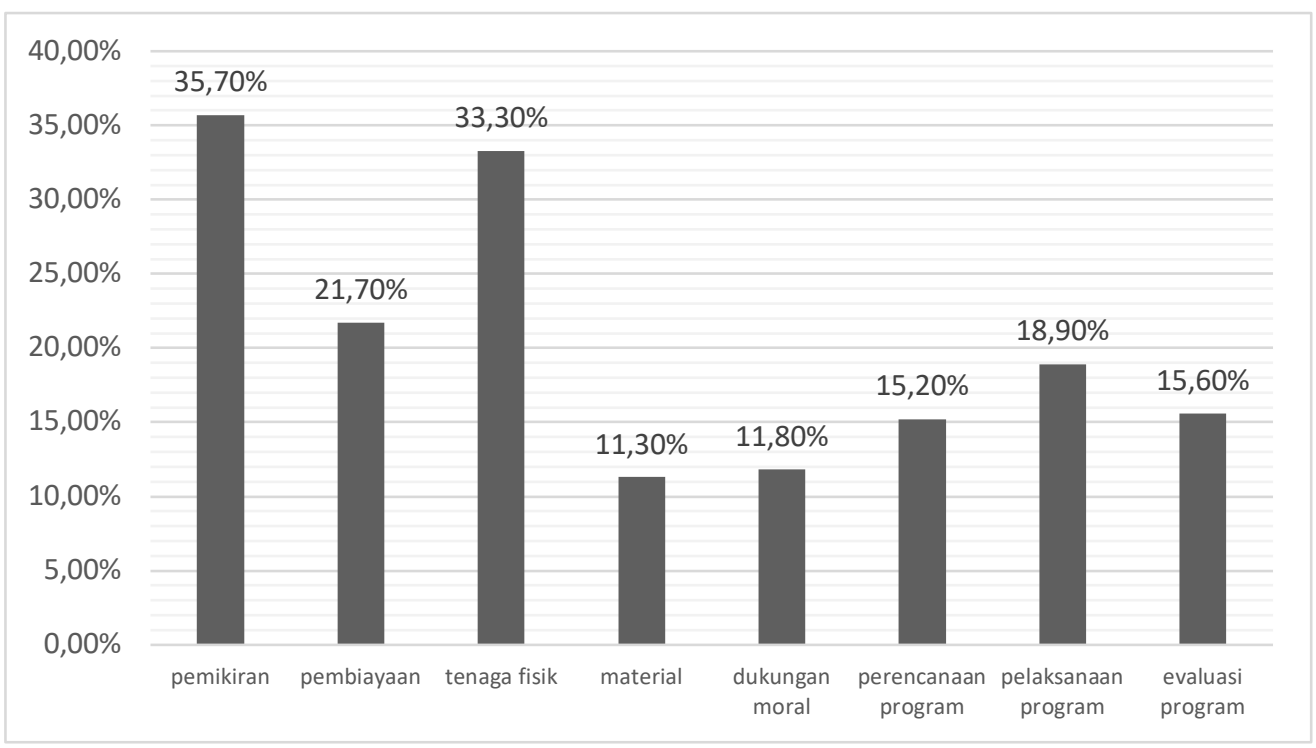

Gambar 3. Grafik Sumbangan Efektif Aspek-aspek Partisipasi Pemuda di Wisata Alam Kalibiru terhadap Ketahanan Ekonomi

Sumber: Analisis data primer (2018)

Besaran sumbangan efektif tersebut menunjukkan pemuda sudah banyak berpartisipasi dalam bentuk pemikiran dan tenaga fisik. Namun ternyata partisipasinya masih kurang efektif pada tahap perencanaan, pelaksanaan, hingga evaluasi program (lihat gambar 4.5). Penjelasannya adalah meski efektivitas partisipasi pemuda tinggi dalam beberapa bidang, posisi mereka dalam pengelolaan Wisata Alam Kalibiru masih sekadar di bagian operasional, bukan manajerial.

Berdasarkan fakta tersebut, dapat diketahui bahwa efektivitas partisipasi pemuda dalam pemikiran dan tenaga fisik yang tinggi sesuai dengan tugas pokoknya yakni bagian operasional di lapangan, begitu juga dengan bentuk pembiayaan dan material. Sedangkan untuk proses manajerial partisipasi pemuda belum signifikan, mengingat kepengurusan inti baik Wisata Alam Kalibiru maupun KSU Mandiri didominasi oleh golongan yang lebih tua.

Berdasarkan pemaparan di atas, maka partisipasi masyarakat secara umum melalui Wisata Alam Kalibiru dan KSU Mandiri, telah sampai pada tingkat tertinggi yakni citizen control (tingkat 8/puncak) yang masuk pada kategori degree of citizen power. Pada tingkatan ini masyarakat memegang kuasa penuh atas program dan manajerial serta dapat melakukan negosiasi langsung dengan pihak luar (Arnstein 1969:222).

Pemerintah menjamin hal ini kepada KSU Mandiri melalui Izin Usaha Pengelolaan Hutan Kemasyarakatan. KSU Mandiri memiliki keleluasaan dalam mengelola hutan kemasyarakatannya, sedangkan pemerintah menjadi membimbing dan mengawasi agar tidak terjadi pelanggaran aturan. Sedangkan partisipasi pemuda sebagai bagian dari masyarakat dianalisis dengan memposisikan Wisata Alam Kalibiru (sebagai unit usaha KSU Mandiri) 
menjadi otoritas menggantikan pemerintah dalam model tangga partisipasi Arnstein. Sehingga partisipasi pemuda dalam pengelolaan Wisata Alam Kalibiru ada pada tingkat placation (tingkat 5) yang masuk pada kategori degree of tokenism.

Tingkatan ini menempatkan beberapa perwakilan pemuda yang dinilai "pantas" (memiliki kapasitas, integritas, dan motivasi tinggi) untuk diberi posisi signifikan dalam pengelolaan Wisata Alam Kalibiru (Arnstein 1969:220). Pemuda yang berkompeten dipercayai untuk, misalnya, mengelola spot-spot foto sebagai ketua grup. Sedangkan manajerial pusat baik Wisata Alam Kalibiru maupun KSU Mandiri tetap dipegang oleh golongan yang lebih tua.

Kesenjangan antara tingkat partisipasi masyarakat dengan tingkat partisipasi pemuda ini sebenarnya sering terjadi dalam masyarakat. Pada lingkup kecil (Dusun Kalibiru dan sekitarnya), kepercayaan penuh hanya dapat muncul kepada orang-orang yang secara konsisten terbukti memiliki kapasitas, integritas, dan motivasi tinggi. Hal ini baru dapat dibuktikan dalam waktu lama, sehingga tidak mengherankan apabila lebih banyak golongan tua yang terbukti mampu (proven) dibandingkan pemuda. Perbandingan antara partisipasi masyarakat umum dengan pemuda di Wisata Alam Kalibiru dapat disimak pada gambar 4.

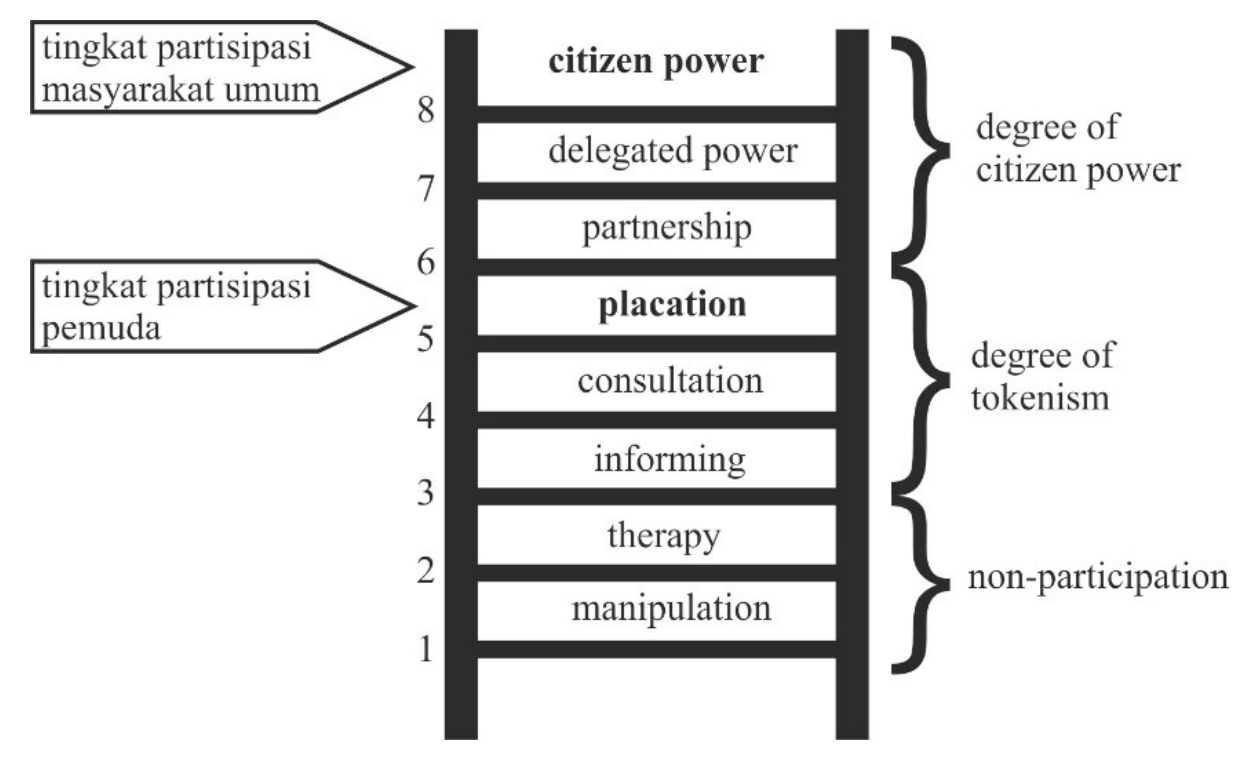

Gambar 4. Posisi Tingkat Partisipasi Masyarakat dan Pemuda di Wisata Alam Kalibiru pada Tangga Partisipasi Arnstein

Sumber : Digambar ulang oleh peneliti dari Arnstein, 1969:217.

Motivasi pemuda sebagai anggota masyarakat untuk terlibat di Wisata Alam Kalibiru menurut Barry dan Barham (2012) di antaranya adalah:

a. rasa kebersamaan komunitas

b. kewajiban sosial, agama, dan tradisional untuk berpartisipasi 
c. melihat peluang untuk memperbaiki kehidupan sendiri dan komunitas

d. remunerasi berupa uang dan sejenisnya

Sistem rekrutmen di Wisata Alam Kalibiru berjalan alami dan mengedepankan hubungan sosial. Sehingga faktor a) dan b) menjadi relevan bagi pemuda. Faktor c) menjadi syarat bagi pemuda agar dapat berpartisipasi di Wisata Alam Kalibiru. Meski faktor-faktor di atas cukup signifikan, pertimbangan utama pemuda berpartisipasi di Wisata Alam Kalibiru adalah faktor d) yaitu remunerasi atau penghasilan. Sedangkan untuk faktor penghambat partisipasi tidak ditemukan faktor yang cukup signifikan. Mayoritas responden menyatakan tidak merasakan hambatan untuk berpartisipasi di Wisata Alam Kalibiru. Hal ini dibenarkan oleh Sudadi selaku Ketua Pengelola Wisata Alam Kalibiru, karena prinsipnya mereka terbuka bagi pemuda yang ingin bergabung meski tetap harus memenuhi beberapa persyaratan seperti motivasi (minat), integritas, dan tanggung jawab.

"Minat, kalau dulu awalnya ditawari. Kalau ditawari tidak mau ya sudah. Tapi setelah itu kan mereka pengen masuk. Di sini pun memang dari awal yang ingin gabung harus ada bentuk lamaran pekerjaan. Apalagi operator, harus ada pelatihan untuk safety dan sebagainya." (Sudadi, wawancara 14 April 2018).

Senada dengan penjelasan di atas, Jans dan de Backer (2002) menyebutkan bahwa pemuda akan berpartisipasi aktif dalam masyarakat apabila terdapat keseimbangan di antara tiga dimensi, yaitu: challenge (tantangan), capacity (kapasitas diri), dan connection (keterhubungan). Hal ini dikonfirmasi oleh Sudadi yang menyebutkan kriteria agar pemuda diterima di Wisata Alam Kalibiru yaitu punya kedekatan geografis dan relasi (connection), punya kemampuan (capacity), dan punya niatan untuk memajukan wilayah (challenge).

'Yang penting punya niatan untuk memajukan wilayah. Karena dengan kami yang tua-tua ini kan dulu harapannya membuat bentuk seperti ini, lapangan pekerjaan untuk tinggalan anak cucu." (Sudadi wawancara 14 April 2018).

Pemuda awalnya tidak terlibat penuh dalam pengelolaan Wisata Alam Kalibiru. Subjek 6 menuturkan awalnya yang terlibat aktif adalah bapak-bapak/orang tua dari para pemuda yang umumnya berprofesi sebagai penggarap lahan. Mereka yang mengawali sejak pengurusan izin (HKm Mandiri) hingga gotong royong pembangunan. Saat itu pemuda orientasinya masih bekerja di luar kota yang dinilai lebih menjanjikan secara finansial. Pemuda baru benar-benar terlibat aktif sejak Wisata Alam Kalibiru dirasa mulai prospektif secara finansial.

"Dulu pemuda ga mau terjun (di Kalibiru) Mas, belum ada duitnya. Bapak-bapak yang aktif, kerja bakti, nyangkul, kan kalau pemuda rata-rata nggak mau kaya gitu. Semua pengen ke luar kota, termasuk saya. Baru gabung beberapa tahun terakhir pas sudah ramai." (Subjek 6 wawancara 14 April 2018). 
Subjek 26 menambahkan, dirinya dulu pernah terlibat di Wisata Alam Kalibiru ketika masih bersekolah. Namun setelah lulus Subjek 26 memutuskan urbanisasi karena Wisata Alam Kalibiru masih sepi. Ketika sudah jenuh di luar kota dan pulang kampung, dia melihat Wisata Alam Kalibiru berkembang. Sehingga dia kembali terlibat di dalamnya dan sekarang menjadi karyawan tetap.

"Sempet kerja luar kota Mas habis lulus SMK. Dulu sempet bantu-bantu di Kalibiru pas sekolah tapi masih sepi, jadi saya ngrantau dulu. Dua tahun lalu pulang kampung dan gabung lagi karena Kalibiru udah rame. Ya Alhamdulillah sudah diangkat tetap.” (Subjek 26 wawancara 13 April 2018).

\section{SIMPULAN}

Partisipasi pemuda di Wisata Alam Kalibiru mayoritas ada pada tingkatan cukup (70\% responden). Dalam model partisipasi Arnstein (1969), partisipasi masyarakat pada pengelolaan Wisata Alam Kalibiru ada pada tingkatan citizen control (tingkat 8/puncak - degree of citizen power), sedangkan partisipasi pemuda ada pada tingkatan placation (tingkat 5 - degree of tokenism). Kesenjangan ini ditunjukkan oleh posisi pemuda dalam pengelolaan yang masih di bawah generasi yang lebih tua.

Tingkat partisipasi pemuda dapat ditingkatkan dengan mulai melibatkan mereka di dalam kepengurusan. Langkah ini sebagai bagian dari estafet kepemimpinan dalam Wisata Alam Kalibiru dengan bimbingan generasi yang lebih tua. Kualitas sumber daya manusia pemuda sendiri juga perlu ditingkatkan. Misalnya dengan membuat pelatihan, sertifikasi di bidang pariwisata. Jika memungkinkan, pengelola dapat memberikan beasiswa bagi pemuda yang ingin berkuliah di bidang pariwisata. Opsi lain adalah dengan bekerjasama dengan lembaga pendidikan tinggi kepariwisataan. Upaya ini penting untuk memunculkan pemuda yang memiliki wawasan dan pengetahuan luas untuk memajukan serta menjamin keberlangsungan Wisata Alam Kalibiru.

\section{DAFTAR PUSTAKA}

2006. Sustainable Tourism: Theory and Practice. Oxford: Elsevier.

Arikunto, S. 2010. Prosedur Penelitian: Suatu Pendekatan Praktik (Edisi Revisi 2010).Jakarta: Rineka Cipta.

Arnstein, S.R., "A Ladder of Citizen Participation". Journal of the American Planning Association, Vol 35: 4, (1969) pp. 216 - 224.

Barry, N., Barham, J. 2012. Review of Existing Practices to Ensure Participation of Disaster-Affected Communities in Humanitarian Aid Operations (Final Report to European Commission). Essex: Aguaconsult.

Creswell, J. W. 2010. Research Design: Pendekatan Kualitatif, Kuantitatif, dan Mixed. Yogjakarta: PT Pustaka Pelajar.

25 | SGSIOGLOBAL : Jurnal Pemikiran dan Penelitian Sasiologi, Vol. 3, No. I, Desember 2018 
Dinas Pariwisata DIY. 2017. Statistik Kepariwisataan 2016. Yogyakarta: Dinas Pariwisata DIY. Suansri, P. 2003. Community Based Tourism Handbook, Bangkok: Responsible Ecological Social Tour.

Sugiyono. 2013. Metode Penelitian Kuantitatif Kualitatif dan R \& D. Bandung: Alfabeta.

Wearing, S. dan Neil, J. 2009. Ecotourism: Impacts, Potentials and Possibilities. Oxford: Elsevier.

Weaver, D.B. (Ed.). 2001. The Encyclopedia of Ecotourism. Wallingford: CAB International. 